\title{
Bio-Toxicity Assessment of PFOA and PFOS to Vibrio Fischeri by Photomultiplier Tube
}

\author{
Jai-yeop Lee ${ }^{1}$, Hyun-dong Lee ${ }^{1,2}$ and Il-ho Kim Lee Le, $^{1, *}$ \\ ${ }^{1}$ Environmental and Plant Engineering Institute, Korea Institute of Civil \\ Engineering and Building Technology, 283 Goyangdae-Ro, Ilsanseo-Gu, Goyang- \\ Si, Korea \\ ${ }^{2}$ University of Science and Technology, Construction and Environment \\ Engineering, 217, Gajeong-ro, Yuseong-gu, Daejeon, Republic of Korea \\ ihkim@kict.re.kr*
}

\begin{abstract}
Bio-toxicity using luminescence of PFOA and PFOS was assessed by photomultiplier tube. The assessment was evaluated based on EC50 and transient profile in time with varying concentration of $0.0 \sim 250 \mathrm{mg} / \mathrm{L}$ in 6 steps. As a result, the toxicity was found out to be 150.3 and 237.7 in EC50 for PFOA and PFOS, respectively. Besides, the profiles depicted that PFOA is more toxic than PFOS. As a result of applying 1CFOK model where actual toxic kinetics were applied, high kinetics parameters showing biological concentration or damage were drawn in case of PFOA. Also, it is determined that PFOA has a significant effect of chronic toxicity on the residual concentration. PFOS does not show a higher toxicity than PFOA, but it shows a fatal toxicity at near $250 \mathrm{mg} / \mathrm{L}$ and it can be concentrated, so measures for this substance are necessary.
\end{abstract}

Keywords: Bio-toxicity, Toxicity assessment, Vibrio fischeri, PFOA, PFOS

\section{Introduction}

Perfluorinated chemicals (hereinafter referred to as PFCs) reduces the surface tension due to the lipophobicity property of fluorocarbons and it is widely used as materials such as surfactant [1-2]. Typical substances among PFCs which are widely used are perfluorooctanoic acid (hereinafter referred to as PFOA) and perfluorooctane sulfonate (hereinafter referred to as PFOS). PFOA is used as a surfactant in the process to produce fluoropolymers such as Teflon1. PFOS is well known as protective agent in Soctchgard which is the brand of $3 \mathrm{M} 2$. When the chemical structure of these two materials is examined, 8 carbons are connected in form of chain, and fluoride is attached to it except for the end. Carboxylic acid and sulfonic acid are connected to each end as the functional group. This allows repulsion from both sides of water and organic solvent, stabilizing the relevant substances. Therefore, these substances are not biodegradable and draw attention as persistent organic pollutants (POPs) which accumulate in the body and show toxicity.

Actually, PFCs are found from various environmental media and human blood plasma [3-4]. This is because PFCs used in the industry are being discharged in large amount and flow and accumulate in various environmental media due to the stable characteristics of substances and remain inside the human body which contacted the environmental media. Research results of monitoring PFCs from the environments also have been reported in the country. PFOA and PFOS were detected up to $405.5 \mathrm{ng} / \mathrm{L}$ and $253.2 \mathrm{ng} / \mathrm{L}$ respectively from Sihwaho Lake in 2005 [5]. The measurement result from sewage influent of sewage treatment plant located in Seoul showed that the maximum PFOA and PFOS were 570 $\mathrm{ng} / \mathrm{L}$ and $254 \mathrm{ng} / \mathrm{L}$ respectively [6]. In addition, when effluent water from sewage treatment plants was measured at the same time, the relevant substances were not processed at all. This suggests that effluent water may flow into natural water system 
again, becomes more concentrated up to the level that could give immediate threat to human body.

In this study, the toxicity evaluation was carried out in order to quantify the toxicity of PFOA and PFOS on living organism. Living organism used for the toxicity evaluation is luminous Vibrio fischeri (hereinafter referred to as V. fischeri). The relevant living organism is a marine living organism which emits light in the metabolic process of energy. Therefore, it has an advantage that biological inhibition due to toxicity is shown directly in the degree of luminescence decrease so that the inhibition dose or lethal dose can be quantified immediately. The toxicity of PFOA and PFOS on V. fischeri according to the concentration was evaluated. Toxicity change in 5 minute intervals was observed upto 30 minutes in order to determine immediate toxicity according to the concentration as well as toxicity effect according to the time.

In order to quantify the toxicity evaluation, the toxicokinetics model was applied. In other word, necessary parameters were drawn by applying one compartment first-order kinetic model (1CFOK), and the reduction of toxicity was predicted by applying the threshold damage model (hereinafter referred to as TDM).

The experimental purposes of this study are as follows.

1. Analyze the transient profile changes in fatal dose of V. fischeri according to the concentration of PFOA and PFOS and time

2. Draw median lethal concentration (hereinafter referred to as LC50 (t)) according to time and median lethal time(hereinafter referred to as LT50 (c)) according to concentration based on No. 1 item above

3. Draw coefficients regarding toxicokinectics of PFOA and PFOS based on the $1 \mathrm{CFOK}$ model

4. Estimate and compare the toxic effects of PFOA and PFOS drawn from toxicokinetics and toxicodynamic coefficients

\section{Methodology}

\section{Chemicals}

PFOA was produced by dissolving perfluorooctanoic acid in powder form in distilled water, and PFOS was produced by diluting heptadecafluorooctanesulfonic acid( $40 \%)$ with distilled water. These two products were purchased from Sigma Aldrich. PFOA and PFOS were produced by reducing the concentration of compounds by half gradually such as $15.6,31.3,62.5,125.0,250.0 \mathrm{mg} / \mathrm{L}$ beginning from $250.0 \mathrm{mg} / \mathrm{L}$. For the reference value, it was compared with the experiment result on blank.

\section{Luminescence analysis}

A test jig where photo multiplier tube (hereinafter referred to as PMT) was installed was used for the toxicity evaluation in this study (Figure 1). In the test jig, the sample cuvette cases and sensors including PMT are installed on assay as the module. The relevant device is designed to detect illumination and fluorescence at the same time and respond to complex species. Up to 8 samples can be analyzed simultaneously, and the analytic sensitivity is $3.0 \times 10^{-21}$ Luciferase.

The test species of Vibrio fischeri used for toxicity evaluation is lyophilized specimen (NRRL B-11177) and the relevant suspension was activated for 30 minutes at the temperature of $15^{\circ} \mathrm{C}$ in the experiment. The experiment was carried out continuously for 30 minutes, and Relative Luminescence Unit (RLU) value was obtained every 5 minutes and set as the reference value. RLU value was normalized and set as the survival rate (\%), and '100 - survival rate (\%)' was considered as the inhibition rate or lethality rate. In order to standardize terminology, inhibition ratio was used for inhibition rate or lethality rate. 


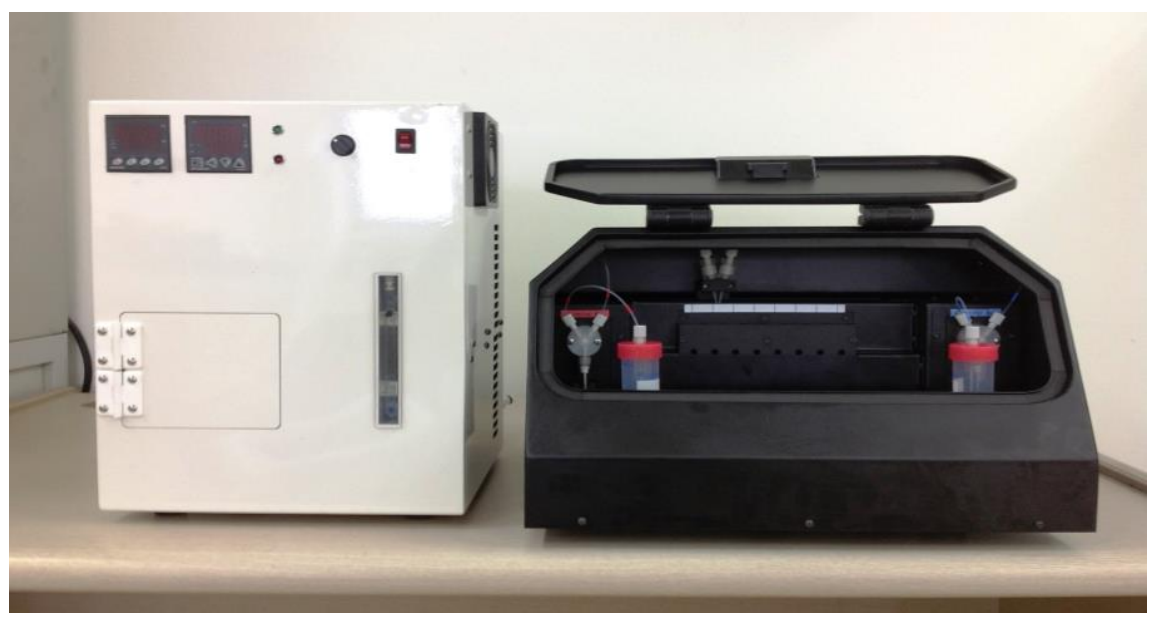

Figure 1. Experimental Device Including PMT

\section{Results and Discussions}

1. Transient profile of luminescence

\section{a. PFOA}

The transient profile changes of V. fischeri's luminescence on PFOA according to time and concentration were shown in Figure 2. y-axis is luminescence and it is used as an indicator showing the inhibition rate. It showed that the inhibition rate increased according to the concentration, and instantaneous lethal dose was shown at 5 minutes for most concentration levels, and it increased steadily even though the increasing amount was a little. More than half died instantaneously at $250 \mathrm{ng} / \mathrm{L}$ which was the highest concentration, showing a survival rate below $20 \%$. According to the trend of graph, it will not reach the half inhibition rate at lower concentration levels. When the time scale was added for consideration, the initial toxicity at 5 minutes in case of a low concentration including $15.6 \mathrm{mg} / \mathrm{L}, 31.3 \mathrm{mg} / \mathrm{L}$ and $62.5 \mathrm{mg} / \mathrm{L}$ increased gradually, showing twice the lethal dose at 30 minutes. Also in case of $125.0 \mathrm{mg} / \mathrm{L}$, the lethal dose increased continuously even though the increasing amount was relatively a little in comparison to the value at 5 minutes. In case of $250 \mathrm{mg} / \mathrm{L}$, there was almost no change in the lethal dose after 10 minutes. This indicates that the toxicity of PFOA on living organism may increase continuously even though the concentration is low. This effect can be seen more clearly by comparing incipient median lethal concentration $(\mathrm{LC} 50, \infty)$ values drawn afterward. LC50, $0_{,}$value of PFOA is $15.87 \mathrm{mg} / \mathrm{L}$ and it predicts that a half of $\mathrm{V}$. fischeri exposed to this concentration chronically dies. This concentration is between $15.6 \mathrm{mg} / \mathrm{L}$ and $31.3 \mathrm{mg} / \mathrm{L}$ and it is expected that it will not show a significant inhibition at the beginning but it may be lethal toxicity in case of being exposed to this concentration for a long period of time. 


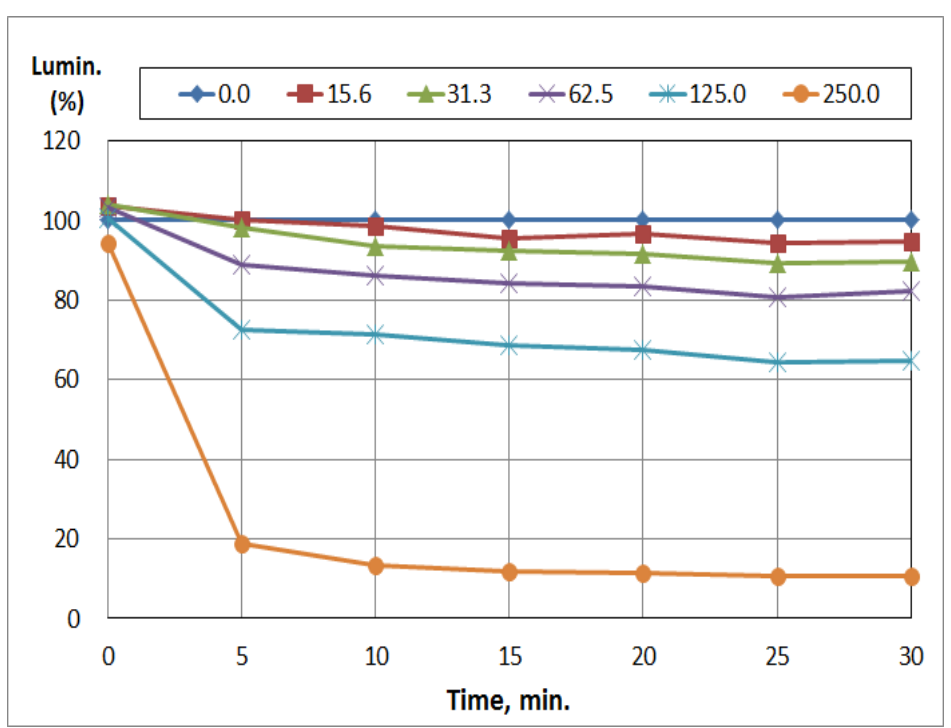

Figure 2. Transient Luminescence Profile V. Fischeri for PFOA

\section{b. PFOS}

The lethal dose of PFOS was shown in Figure 3. The basic composition of graph is same with Figure 2. It shows a similar trend with PFOA, and the concentration which exceeds instantaneous lethal dose for a half is limited to $250 \mathrm{mg} / \mathrm{L}$. Meanwhile, the lethal dose increased little by little at all concentration levels as time went on. The overall toxicity of PFOS was lower than that of PFOA. LC50, $\infty$ of PFOS was $224.8 \mathrm{mg} / \mathrm{L}$, and it shows that the influence from being exposed for a long period of time has decreased to a certain degree. This is because the absolute influence of toxicity from the concentration has decreased.

The analysis result of transient profile changes of abnormality shows that PFCs has acute toxicity to V. fischeri, and the criticality is decided based on $250 \mathrm{mg} / \mathrm{L}$. However, the toxicity from prolonged exposure even at a lower concentration cannot be ignored. Meanwhile, it is expected that the toxicity of PFOA is higher than that of PFOS.

There is a limitation in the interpretation of transient profile evaluation on abnormality. Therefore, a quantitative analysis method is required. Applicable methods include the statistical method and the model analysis method based on toxicokinetics and toxicodynamics.

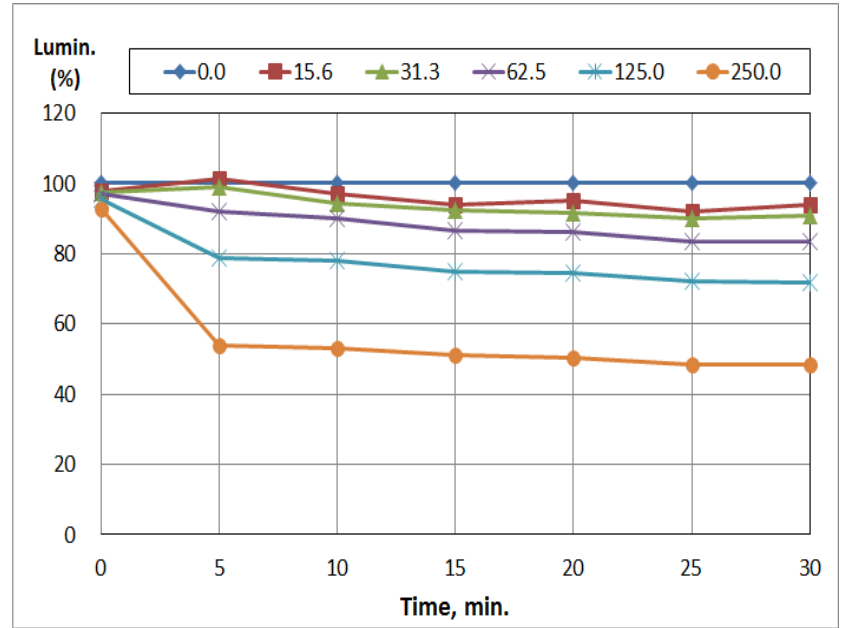

Figure 3. Transient Luminescence Profile V. Fischeri for PFOS 


\section{2. $1 \mathrm{CFOK}$}

1CFOK supposes material balance by classifying quantification on biological concentration into two factors including concentration and removal as follows [7].

$$
\frac{d R}{d t}=k_{u} c(t)-k_{e} R
$$

$\mathrm{R}$ is the body residue $\left(\mathrm{mol} \cdot \mathrm{kg}^{-1}\right), \mathrm{c}(\mathrm{t})$ is the water concentration $\left(\mathrm{mol} \cdot \mathrm{L}^{-1}\right), \mathrm{k}_{\mathrm{u}}$ is the uptake rate coefficient $\left(\mathrm{L} \cdot \mathrm{kg}-1 \cdot \min ^{-1} 1\right)$, and $\mathrm{k}_{\mathrm{e}}$ is the elimination rate constant $\left(\min ^{-1} 1\right)$.

A constant threshold exists in toxicity of a certain compound on living organism for exposure concentration or time and it is called narcosis hypothesis. A specific method to apply this is to suppose critical body residue. In toxicokinetics, a threshold of body residue which leads $50 \%$ death rate is called critical body residue (hereinafter referred to as CBR, mol $\left.\cdot \mathrm{kg}^{-1} 1\right)$. CBR may be constant or change over time. In order to draw proper parameters of toxicokinetics from limited material, $1 \mathrm{CFOK}$ model can be applied as follows by supposing a constant value for CBR [8].

$$
\mathrm{CBR}=\mathrm{LC}_{50}\left(\mathrm{k}_{\mathrm{u}} / \mathrm{k}_{\mathrm{e}}\right)\left(1-\mathrm{e}^{-\mathrm{ket}}\right)
$$

The equation shown above is what relation of 1CFOK to the exposure time with LC50. $\mathrm{LC}_{50}$ is the concentration that $50 \%$ is inhibited or ceases to exist at the relevant time. The toxicity on living organisms is influenced by concentration as well as exposure time as reviewed above. The equation above shows the amount of toxic substances accumulated in human body through the combination between LC50 and time factors.

Meanwhile, it is possible to obtain a time function including several parameters as follows by arranging the equation above for LC50. $\mathrm{k}_{\mathrm{u}} / \mathrm{k}_{\mathrm{e}}$ which is the ratio between the concentration and removal velocity coefficient is called bioconcentration factor (hereinafter referred to as BCF, $\left.\mathrm{L}_{\mathrm{kg}} \mathrm{kg}^{-1}\right)$. Therefore, $\mathrm{CBR} /\left(\mathrm{k}_{\mathrm{u}} / \mathrm{k}_{\mathrm{e}}\right)$ can be expressed with $\mathrm{CBR} / \mathrm{BCF}$. A proper parameter value can be obtained by setting $\mathrm{CBR} / \mathrm{BCF}$ as one parameter and comparing it with actual LC50.

$$
\mathrm{LC}_{50}(\mathrm{t})=\left(1-\mathrm{e}^{-\mathrm{ket}}\right)^{-1} \cdot \mathrm{CBR} / \mathrm{BCF}
$$

LC50 (t) per time according to the experiment result could be obtained using probit statistics model provided by EPA ${ }^{9}$. And, $\mathrm{k}_{\mathrm{e}}$ and $\mathrm{CBR} / \mathrm{BCF}$ values could be obtained by applying $\mathrm{LC}_{50}$ value obtained from Probit model to the model equation. These coefficient values and experiment and calculation values of $\mathrm{LC}_{50}$ were compared and shown in Table 1.

\section{Table 1. Comparison of LC50 ( $t$ ) between Probit Analysis and Calculated} Values

\begin{tabular}{ccccc}
\hline & \multicolumn{2}{c}{ PFOA } & \multicolumn{2}{c}{ PFOS } \\
$\mathrm{T}$ & Probit & Calculated & Probit & Calculated \\
\hline 5 & 155.6 & 155.6 & 271.6 & - \\
10 & 140.9 & 133.8 & 324.1 & - \\
15 & 133.2 & 130.8 & 323.3 & 323.3 \\
20 & 130.2 & 130.3 & 301.4 & 297.3 \\
25 & 121.7 & 130.2 & 292.3 & 284.9 \\
30 & - & 130.2 & 276.0 & 278.5 \\
\hline $\mathrm{k}_{\mathrm{e}}$ & & 0.3622 & & 0.1218 \\
$\mathrm{CBR} / \mathrm{BCF}$ & & 130.2 & & 271.3 \\
\hline
\end{tabular}


In addition to concentration, time is also a factor which corresponds to inhibition or lethality. It was also shown in Figures 2 and 3 that the lethal dose increased over time. The time that a half dies at a constant concentration is called median lethal time (LT50(c)). Therefore, LT50(c) can be obtained as a value for each concentration level. The method to obtain $\mathrm{LT}_{50}$ (c) is to use logarithms graph from the slope of lethal dose over time. LT50(c) can be obtained from the slope and intercept of return line shown in this graph. $\mathrm{LT}_{50}(\mathrm{c})$ obtained is as follows.

Table 2. LT50 (c) Values of PFOA and PFOS by Logarithms Method

\begin{tabular}{ccccccc}
\hline \multirow{4}{*}{ PFOA } & & 15.6 & 31.3 & 62.5 & 125.0 & 250.0 \\
& slope & -0.034 & -0.052 & -0.050 & -0.072 & -0.313 \\
& intercept & 4.661 & 4.665 & 4.568 & 4.416 & 3.376 \\
& $\mathrm{LT}_{50}$ & $4.49 \times 10^{9}$ & $1.90 \times 10^{6}$ & 519,485 & 1,041 & 0.181 \\
\hline \multirow{3}{*}{ PFOS } & slope & -0.041 & -0.050 & -0.059 & -0.055 & -0.066 \\
& intercept & 4.666 & 4.668 & 4.623 & 4.464 & 4.107 \\
& $\mathrm{LT}_{50}$ & $1.08 \times 10^{8}$ & $3.35 \times 10^{6}$ & 165,336 & 22,213 & 18.85 \\
\hline
\end{tabular}

LT50 (c) can be expressed as follows also by 1CFOK [10].

$$
\mathrm{LT} 50(\mathrm{c})=-\left(1 / \mathrm{k}_{\mathrm{e}}\right) \ln \left(1-\mathrm{LC}_{50, \infty} / \mathrm{c}\right)
$$

$\mathrm{LC} 50,{ }_{\infty}$ is incipient $\mathrm{LC}_{50}$, and c is the concentration exposed to the water system. LC50, $\infty$ can be obtained by comparing LT50(c) value obtained from logarithms with the model equation. It is $15.87 \mathrm{mg} / \mathrm{L}$ and $224.8 \mathrm{mg} / \mathrm{L}$ respectively for PFOA and PFOS (Table 3). It means that in case of PFOA, toxicity increases continuously at the concentration of 15.87 $\mathrm{mg} / \mathrm{L}$ and the lethality rate reaches $50 \%$. In case of PFOS, it is $224.8 \mathrm{mg} / \mathrm{L}$ which is a relatively high concentration level. This means that PFOA has a higher toxicity and PFOS has a less toxicity influence over a long period of time at a relatively low concentration.

Table 3. Incipient LC50 and ku Values of PFOA and PFOS

\begin{tabular}{ccc}
\hline & PFOA & PFOS \\
\hline $\mathrm{LC}_{50, \infty}$ & 15.87 & 224.8 \\
$\mathrm{k}_{\mathrm{u}}$ & $5.54 \times 10^{-4}$ & $9.10 \times 10^{-5}$ \\
$\mathrm{BCF}$ & $1.92 \times 10^{-5}$ & $9.21 \times 10^{-6}$ \\
\hline
\end{tabular}

When $\mathrm{c}(\mathrm{t})$ is constant and $\mathrm{R}(0)$ is 0 in the material balance equation for the body residue above, the relevant equation can be summarized as follows.

$$
\mathrm{R}(\mathrm{t}) \quad=\left(\mathrm{k}_{\mathrm{u}} / \mathrm{k}_{\mathrm{e}}\right) \mathrm{c} \cdot\left(1-\mathrm{e}^{-\mathrm{ket}}\right)
$$

$\mathrm{ku}$ value can be obtained from CBR/BCF. CBR value should be obtained first, but it is impossible to obtain CBR directly from the experiment data of this study. Therefore, an appropriate estimation method is necessary. McCarty presented the following initial CBR from the relationship between $\mathrm{LC}_{50}, \mathrm{BCF}$ and $\mathrm{K}_{\mathrm{Ow}}[11]$.

$$
\mathrm{CBR}=2.5 \mathrm{mmolkg}^{-1} \text { wet weight }
$$

When $\mathrm{k}_{\mathrm{u}}$ is calculated from this, it is $5.54 \times 10^{-4}, 9.10 \times 10^{-5} \mathrm{~L} \cdot \mathrm{kg}^{-1} \cdot \mathrm{min}^{-1}$ for PFOA and PFOS respectively (Table 3 ). The accumulated body residue amount over time based on the obtained values was shown in Figures 4 and 5. According to the transient profile slope, body accumulated speed shown in PFOA was faster. The elimination velocity constant is 
higher in comparison to PFOS, but it's because uptake velocity constant is higher than that. This can be proven by comparing it with $\mathrm{BCF}$ value on the grounds. The comparison result showed that $\mathrm{BCF}$ value of PFOA is somewhat higher. According to the trend of graph, it may be difficult to apply constant CBR. Therefore, it is reasonable to apply $\mathrm{CBR}(\mathrm{t})$ model which is expressed as time function for the relevant toxicity evaluation.

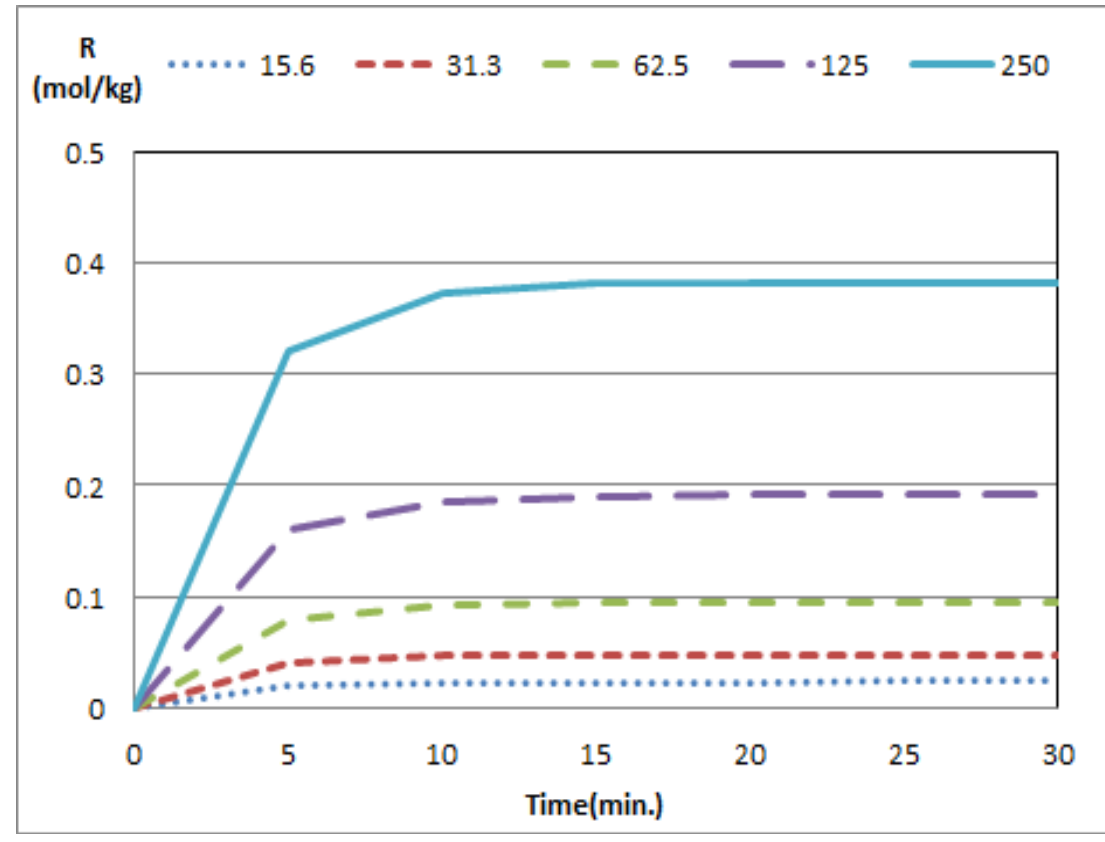

Figure 4. Body Residue in V. Fischeri by Time for PFOA

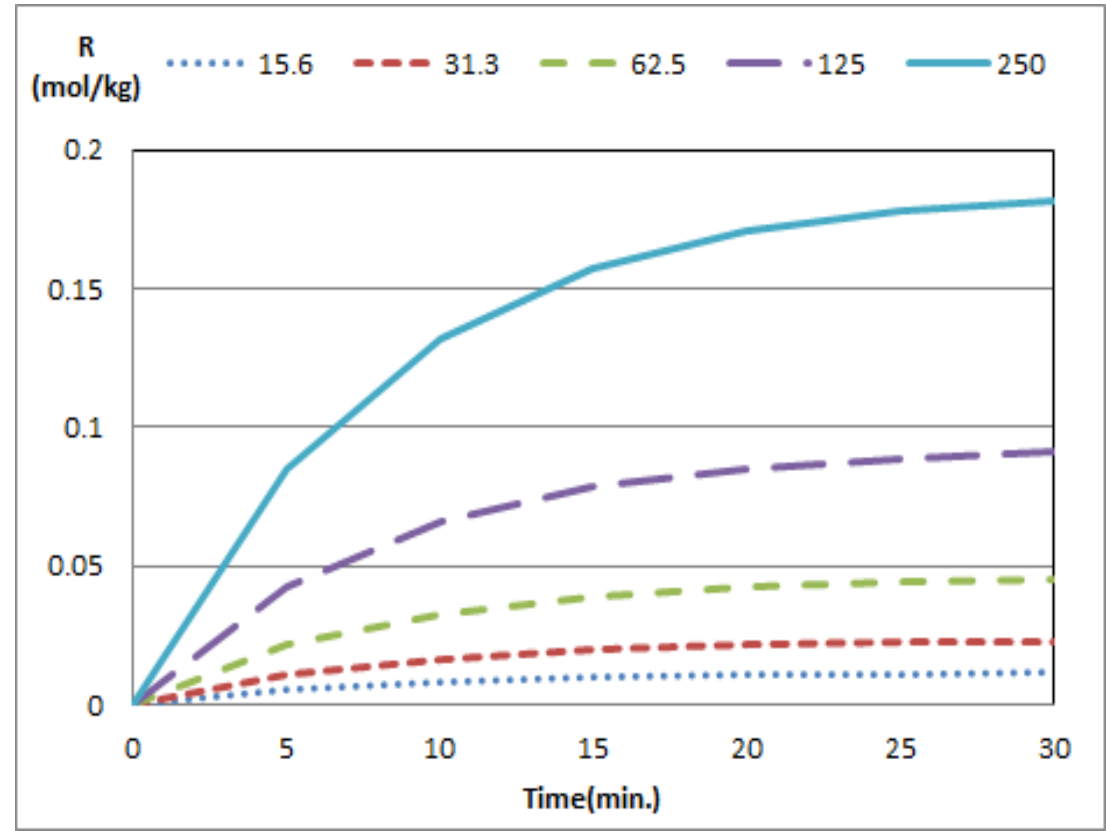

Figure 5. Body Residue in V. Fischeri by Time for PFOS

\section{Damage Assessment Model and Threshold Damage Model}

In Toxicodynamics, the correlation on inhibition rate or lethality rate in body residue is 
expressed by using a function called 'damage'. In the damage assessment model (hereinafter referred to as DAM) which was the most common damage model, damage applied to organism was shown as time function $D(t)$ [12]. $D(t)$ is expressed in material balance equation by classifying into two functions including concentration and recovery similar to $\mathrm{R}(\mathrm{t})$. The biological concentration was obtained from the body residue which was obtained earlier and $\mathrm{k}_{\mathrm{a}}\left(\mathrm{mol}^{-1} \cdot \mathrm{kg} \cdot \mathrm{h}^{-1}\right)$ which was damage accrual rate coefficient was set as correlation coefficient. The recovery was shown as scaling function of $\mathrm{k}_{\mathrm{r}}\left(\mathrm{min}^{-1}\right)$ which was damage recovery rate constant showing the recovery rate from $\mathrm{D}(\mathrm{t})$ indicating damage. The following equation can be obtained.

$$
\frac{d D}{d t}=k_{a} R-k_{r} D
$$

When $D(0)$ is 0 and the external concentration is constant, $D(t)$ can be integrated as follows.

$$
D(t)=k_{a} \frac{k_{u}}{k_{e}} C_{w}\left(\frac{e^{-k r t}-e^{-k e t}}{k_{r}-k_{e}}+\frac{1-e^{-k r t}}{k_{r}}\right)
$$

Assuming that when $\mathrm{D}(\mathrm{t})$ reaches a certain damage, it is considered that it has reached $\mathrm{LC}_{50}(\mathrm{t})$ half lethality, and it is regarded as DL, then LC50(t) can be expressed as follows ${ }^{10}$.

$$
L C_{50}(t)=\frac{D_{L} / k_{a}}{\frac{k_{u}}{k_{e}}\left(\frac{e^{-k r t}-e^{-k e t}}{k_{r}-k_{e}}+\frac{1-e^{-k r t}}{k_{r}}\right)}
$$

Here, when we consider $D_{\mathrm{L}} / \mathrm{k}_{\mathrm{a}}$ as a constant, an appropriate value could be obtained with $\mathrm{k}_{\mathrm{r}}$ together using the fitting method with previous LC50 (t) data. $\mathrm{kr}$ value is 0.4928 , $0.3397 \mathrm{~min}^{-1}$ respectively, showing that the recovery is faster in case of PFOA, but damage applied to organism should be considered with body residue, $\mathrm{k}_{\mathrm{a}}$ together.

Table 4. The obtained $D_{L} / k_{a}$ and $k_{r}$ for PFOA and PFOS

\begin{tabular}{ccc}
\hline & PFOA & PFOS \\
\hline $\mathrm{D}_{\mathrm{L}} / \mathrm{k}_{\mathrm{a}}$ & 128.8 & 292.1 \\
$\mathrm{k}_{\mathrm{r}}$ & 0.4928 & 0.3397 \\
\hline
\end{tabular}

The threshold damage model (hereinafter referred to as TDM) can be applied as function to obtain the lethal dose from the Damage function [13]. This model has been established based on the assumption that when damage obtained from DAM exceeds a certain threshold value, it influences the survival probability from that moment. The expression is as follows.

$$
\begin{gathered}
\frac{\mathrm{dH}(\mathrm{t})}{\mathrm{dt}}=\theta \cdot \max [\mathrm{D}(\mathrm{t})-\text { threshold }, 0] \\
\mathbf{S}=\mathbf{e}^{-\mathbf{H}(\mathrm{t})}
\end{gathered}
$$

$\theta$ is a constant which connects the survival probability and the damage, and threshold is a threshold value which indicates the toxicity in the relevant living organism. When the 
value does not exceed threshold, the toxicity does not appear. $\mathrm{S}$ is the survival probability. The threshold value and $\theta$ obtained from the relevant experiment value is as shown in the following table.

In this study, $\mathrm{k}_{\mathrm{a}}$ and threshold values were estimated by carrying out regression analysis on the relations between survival probability, $S$ abstained above and luminescence value of $\mathrm{V}$. fischeri. As a limitation of model equation, a value combined with $\theta$ value was shown (Table 5). The calculation result shows that there was no separate threshold value for the relevant equation.

Table 5. The Obtained ka and threshold Values Multiplied by $\theta$ for PFOA and PFOS

\begin{tabular}{ccc}
\hline & PFOA & 6PFOS \\
$\theta \cdot \mathrm{k}_{\mathrm{a}}$ & 5.14 & 5.06 \\
$\theta \cdot$ thershold & - & - \\
\hline
\end{tabular}

The parameters obtained earlier and the graph of actual transient profile changes were shown in Figures 6 and 7 for comparison. The toxicity value by actual model equation is similar to the experiment value but it is somewhat different in case of concentration levels such as $250.0 \mathrm{mg} / \mathrm{L}$ which show strong toxicity at the beginning. This seems to be a limitation of model equation which is expressed in a linear function. Meanwhile, the toxicity values matched relatively well at low concentration ranges indicating continuous toxicity increase.

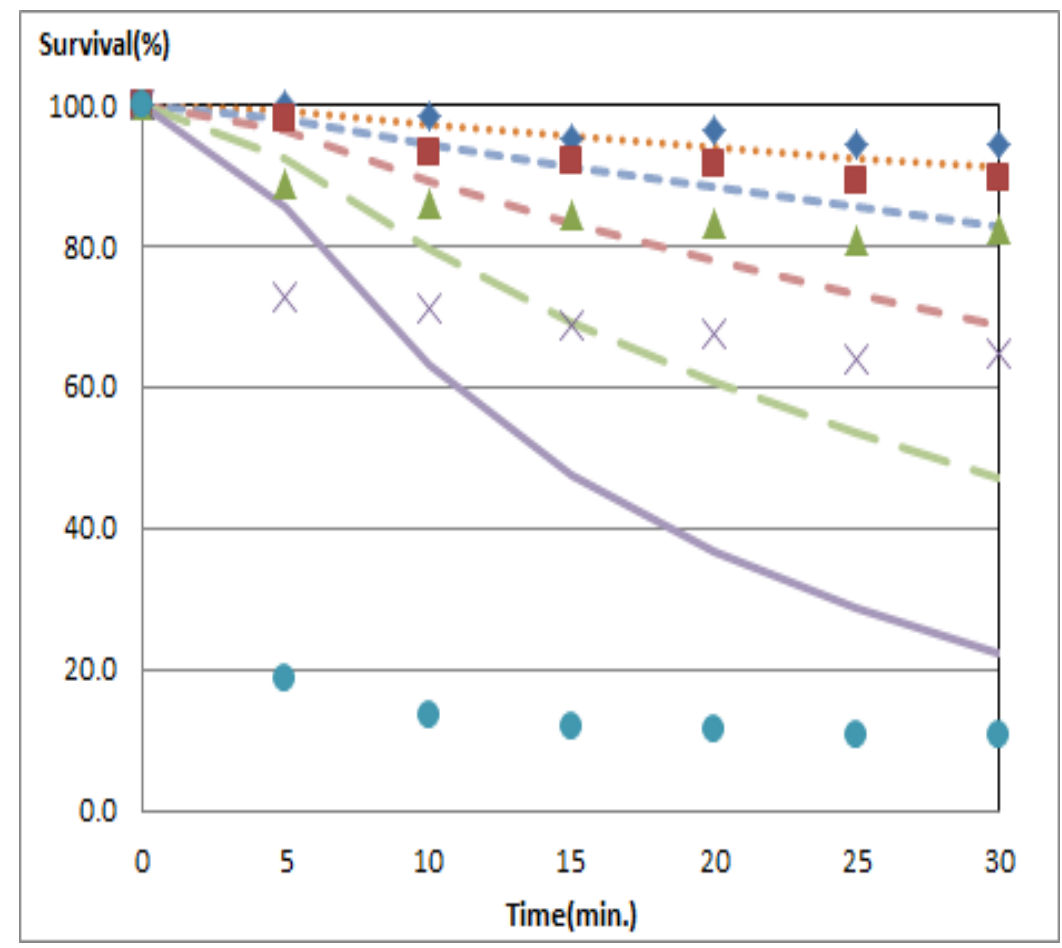

Figure 6. Comparison between Experimental and Calculated Values for PFOA: Points(Experimental Values, $\diamond: 15.6$, , : 31.3, $\triangle: 62.5, \times: 125.0, \bullet$ : 250.0), Line(Calculation, ... : 15.6, --- : 31.3 , ——— : 62.5, - - : 125.0 , Line : 250.0), Units are $\mathrm{mg} / \mathrm{L}$ 


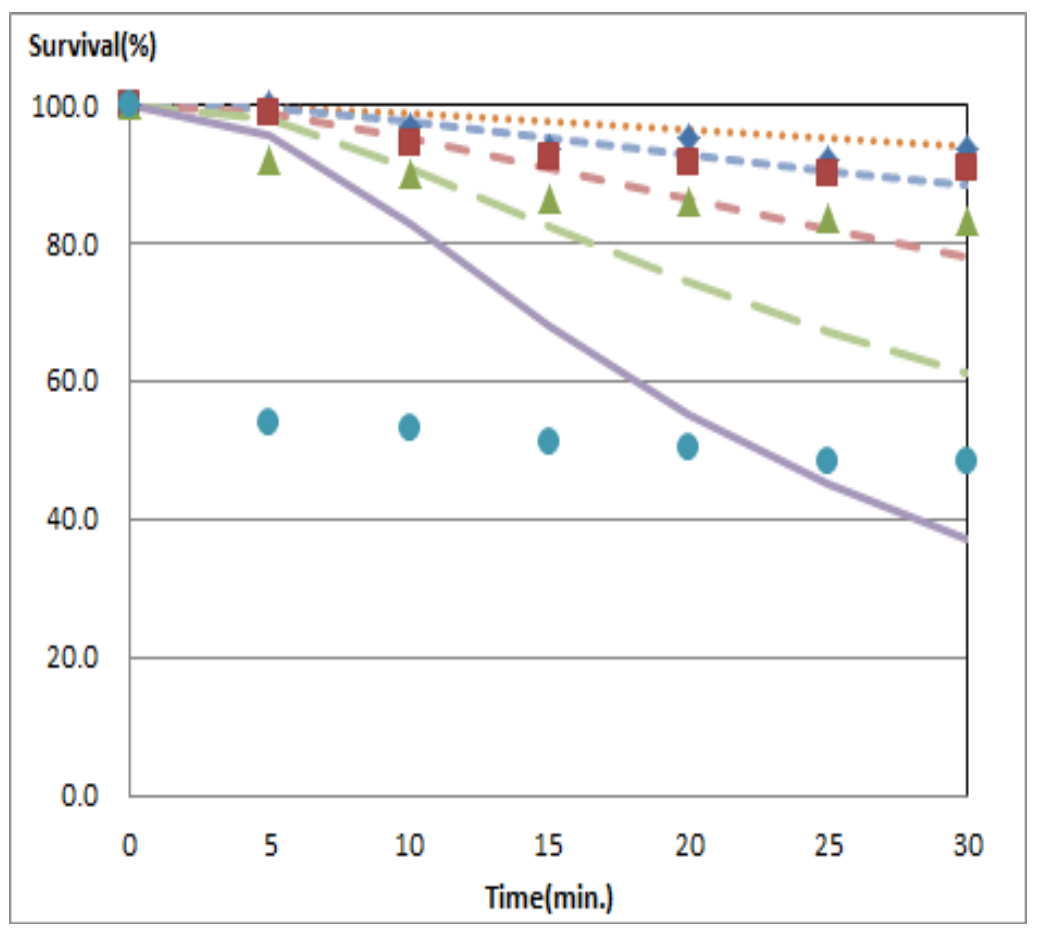

Figure 7. Comparison between Experimental and Calculated Values for PFOS: Points(Experimental Values, $\bullet: 15.6$, a : 31.3, $\triangle:$ 62.5, $\times: 125.0, \bullet$ : 250.0), Line(Calculation, ... : 15.6, --- : 31.3 , ——— : 62.5, - - : 125.0 , Line : 250.0), Units are $\mathrm{mg} / \mathrm{L}$.

\section{Conclusions}

In this study, the toxicity evaluation of PFOA and PFOS which were typical PFCs found in small quantity from environmental media on $\mathrm{V}$. fischeri was carried out. The inhibition rate or lethality rate was determined from luminescence over time and concentration, and LC50(t) and LT50(c) were obtained from the determined inhibition rate or lethality rate. And, each parameter value was obtained from the toxicity velocity model.

1. The transient profile survival rate on PFOA decreased drastically at $250 \mathrm{mg} / \mathrm{L}$ and dropped below the lethality rate of $20 \%$ within 5 minutes. After 10 minutes, there was no significant lethality rate change. At a lower concentration level, the lethality rate was proportional to concentration, but no rapid survival rate drop shown in case of $250 \mathrm{mg} / \mathrm{L}$ was not shown. On the other hand, the survival rate decreased gradually at $62.5 \mathrm{mg} / \mathrm{L}$ and $125.0 \mathrm{mg} / \mathrm{L}$. It was shown that the lethality rate of PFOS was lower than that of PFOA. In case of $250.0 \mathrm{mg} / \mathrm{L}$, the lethality rate came close to $50 \%$ until 30 minutes, but there was no significant change at other low concentration levels.

2. The range of $\mathrm{LC}_{50}$ was between $121.7 \mathrm{mg} / \mathrm{L}$ and $155.6 \mathrm{mg} / \mathrm{L}$ in case of PFOA and between $276.0 \mathrm{mg} / \mathrm{L}$ and $324 \mathrm{mg} / \mathrm{L}$ in case of PFOS, indicating that PFOA had stronger toxicity than PFOS. LT50 was 0.181 minute in case of PFOA and 18.85 minutes in case of PFOS at $250.0 \mathrm{mg} / \mathrm{L}$, showing that the toxicity of PFOA was also higher than that of PFOS.

3. As a result of analyzing the relevant experiment result through the toxicity velocity model equation of $1 \mathrm{CFOK}$ model by assuming CBR as constant, $\mathrm{k}_{\mathrm{u}}$ indicating the intake velocity of harmful substance was $5.54 \times 10^{-4}$ and $9.10 \times 10^{-5}$ respectively at PFOA and PFOS, showing that PFOA the relevant living organism takes in PFOA more. $\mathrm{k}_{\mathrm{e}}$ indicating the harmful substance removal velocity was 0.3622 and 0.1218 min-1 
respectively, showing that the removal velocity of PFOA was better than that of PFOS. BCF which was an overall indicator of these results was $1.92 \times 10^{-5}$ and $9.21 \times 10^{-6} \mathrm{~L}_{\mathrm{kg}} \mathrm{kg}^{-1}$ respectively for PFOA and PFOS showing that PFOA had a higher value. Each incipient $\mathrm{LC}_{50}$ obtained from LT50(c) was $15.87 \mathrm{mg} / \mathrm{L}$ and $224.8 \mathrm{mg} / \mathrm{L}$ respectively.

4. The relevant threshold value did not appear when the Threshold model was applied. This is because Vibrio fischeri which had relatively small biomass showed a sensitive response to the toxicity. The fact that no same trend on high concentration levels showing acute toxicity was shown due to the limitation of model equation was also a reason that it was unable to obtain the threshold value.

The toxicity of PFOA and PFOS was confirmed through the toxicokinetcis and toxicodynamics analysis using the 1CFOK model. The test jig installed with PMT used in this study shows instantaneous toxicity on V. fischeri so that it is expected that the toxicity evaluation can be carried out for a new substance which toxicity is unknown within a short period of time by using it. A significant study to predict complex toxicity on living organism in actual environments or water system will be necessary in future. For this, studies on proper toxicokinetics to predict complex toxicity or rational models based on toxicodynamics should be carried out continuously in future.

\section{References}

[1] Wikipedia, "perfluorooctanoic acid(PFOA)", http://en.wikipedia.org

[2] Wikipedia, "perfluorooctanesulfonic acid(PFOS)", http://en.wikipedia.org

[3] Martin J. W., Muir D. C. G., Moody C. A., Ellis D. A., Kwan W. C., Solomon K. R. and Mabury S. A., "Collection of airborne fluorinated organics and analysis by gas chromatography/chemical ionization mass spectrometry", Analytical Chemistry, vol. 74, (2002), 584-590.

[4] Stock N. L., Lau F. K., Ellis D. A., Martin J. W., Muir D. C. G. and Mabury S. A., "Polyfluorinated telomer alcohols and sulfonamides in the north American troposphere", Environmental Science \& Technology, vol. 39, (2004), pp. 991-996.

[5] Kannan K., Giesy J. P., Rostkowski P., Yamashita N., So M. K., Taniyasu S., Lam P. K. S., Falandysz J., Lee K. T., Kim S. K., Khim J. S., Im S. H ., Newsted J. L. and Jones P. D., "Perfluorinated compounds in streams of the shihwa industrial zone and lake shihwa, South Korea", Environmental Toxicology and Chemistry, vol. 25, (2006), pp. 2374-2380.

[6] Shin M. Y., Im J. K., Kho Y. L., Choi K. S. and Zoh K. D., "Quantitative Determination of PFOA and PFOS in the Effluent of Sewage Treatment Plants and in Han River”, J. Env. Hlth. Sci., vol. 35, no. 4, (2009), pp. 334-342.

[7] Hawker D. W. and Connell D. W., "Relationships between partition coefficient, uptake rate constants, and the time to equilibrium for bioaccumulation", Chemosphere, vol. 14, (1985), pp. 1205-1219.

[8] McCarty L. S., Ozburn G. W., Smith A. D., Bharath A., Orr D. and Dixon D. G., "Hypothesis formulation and testing in aquatic bioassays: a deterministic model approach", Hydrobiologia, vol. 188, (1989), pp. 533-542.

[9] EPA, "Benchmark Dose Model Executables", http://www.epa.gov/ncea/bmds/.

[10] Lee J. H., "Toxicokinetic and Toxicodynamic Models for Ecological Risk Assessment", J. ENVIRON. TOXICOL. vol. 24, no. 2, (2009), pp. 79-93.

[11] McCarty L. S., Mackay D., Smith A. D., Ozburn G. W. and Dixon D. G., "Residue-based interpretation of toxicity and bioconcentration QSARs from aquatic bioassays: neutral narcotic organics", Environ Tox Chem., vol. 11, (1992), pp. 917-930.

[12] Lee J. H., Landrum P. F. and Koh C. H., "Prediction of time dependent PAH toxicity in Hyalella azteca using a damage assessment model”, Environ Sci. Technology, vol. 36, (200), pp. 3131-3138.

[13] Ashauer R., Boxall A. B. A. and Brown C. D., "New ecotoxicological model to simulate survival of aquatic invertebrates after exposure to fluctuating and sequential pulses of pesticides", Environ Sci. Technology, vol. 41, (2007), pp. 1480-1486. 


\section{Authors}

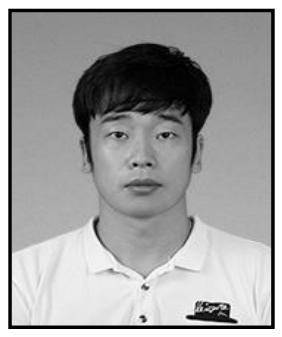

Jaiyeop Lee, Korea, Ph. D., Environmental Engineering, Environmental and Plant Engineering Institute, Korea Institute of Civil Engineering and Building Technology.

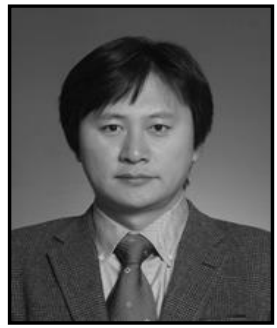

Ilho Kim, Korea, Ph. D., Environmental and Plant Engineering Institute, Korea Institute of Civil Engineering and Building Technology, Dept. of Construction and Environment Engineering, University of Science and Technology.

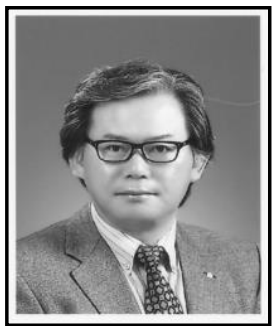

Hyun-dong Lee, Korea, Ph. D., Environmental and Plant Engineering Institute, Korea Institute of Civil Engineering and Building Technology, Dept. of Construction and Environment Engineering, University of Science and Technology. 